Editorial

\title{
Introduction: Mapping cultural intangibles
}

Keywords:

Mapping culture

Making the intangible visible

\section{Cultural mapping: an emerging interdisciplinary field}

Cultural mapping is a practical, participatory planning and development tool and an emerging mode of research (Duxbury, Garrett-Petts \& MacLennan, 2015). While cultural mapping has come to be closely associated with professional cultural planning practices, ${ }^{1}$ its recent adoption within a variety of disciplinary areas means that "traditional" approaches are being re-thought and expanded, with cultural mapping practices adopting new methodologies, perspectives, and objectives as they evolve. This growing, widespread interest in cultural mapping reflects the spatial, placed-based turn in cultural and artistic studies, architecture and urban design, geography, sociology, cultural policy and planning, and e-media studies, among other areas.

The origins of this special issue of City, Culture and Society are found in a selection of papers originally presented at the international conference "Mapping Culture: Communities, Sites and Stories," which was organized by the Centre for Social Studies at the University of Coimbra, Portugal, May 28-30, 2014. The conference explored both conventional and alternative approaches to mapping cultures and communities in an international context. The selected papers have been peer reviewed and revised for this issue.

From a pragmatic perspective, cultural mapping is defined as "a process of collecting, recording, analyzing and synthesizing information in order to describe the cultural resources, networks, links and patterns of usage of a given community or group" (Stewart, 2007: 8 ). This special issue contributes to the development of methodologies for employing cultural mapping as a means of gathering, analyzing, and disseminating ideas and information. In particular, it aims to advance our conceptualization and understanding of diverse approaches to mapping intangible dimensions of culture, and to synthesize some insights from these approaches to advance methodological practice in this area. As Duxbury et al. (2015) point out,

\footnotetext{
${ }^{1}$ For an examination of contemporary approaches to integrating cultural mapping within planning contexts, see Duxbury and Jeannotte (2015).

Methodologically, if one accepts that the intangible, the subjective, and the immaterial are important to what culture is as an object of study, then quantitative methods alone are inadequate. This interest in making the intangible visible heightens the importance of drawing on cultural research traditions that are primarily qualitative in nature and, in some cases, drawing on ethnographic and artistic traditions of inquiry. (p. 18)

As a mode of research that enables a clear organizing structure to hold together hybrid modes of information, cultural mapping has emerged as a useful tool in diverse research fields from artistic inquiry to community governance. The map itself can embed spatial and chronological information, description, narrative, sound, moving and still images, and both quantitative and qualitative data through a visual interface that carries affective and stylistic qualities as well as "basic" information. The process of mapping often reveals many unexpected resources and builds new cross-community and cross-sector connections.

Cultural mapping methodologies hold great potential as a bridging methodology for interdisciplinary projects, and in particular to bridge forms of artistic inquiry with research based in other disciplines. Maps can provide ways in which to see and understand our world in micro and macro, through different perspectives, scales, senses, and values. Depending on the ontology and the instruments applied, mapping can be a colonizing, territorial practice - or a way of undoing languages of territory and privatization. In his book Dark Writing, historian, philosopher and artist Paul Carter stresses the importance of including non-linear logics in mapping practices and contends that "it doesn't matter how maps are redrawn unless they are drawn differently" (Carter, 2009: 7). The term dark writing refers to the illusive, liminal, only-partiallycoherent voices of the world, the messages and moments that generally sit below our awareness but which are always nevertheless there, the "patterns of meeting that cannot be represented or prescribed" (p. 2). Carter's objective is to propose approaches to a kind of mapping and writing "differently" - with an artistry of listening and attending that allows the dark writing of the world to manifest. Taking such listening into material forms requires intuitive leaps of imagination, with the dynamic character of environments becoming agents that lead to realization of cartographic form: "Even if the dark writing of the world cannot be represented, its absence can be registered ... traces of what is missing can shine through" (p. 3).

A second example of mapping as a bridging methodology to artistic approaches is Dennis Wood's book Everything Sings: Maps for a Narrative Atlas (Wood, 2010), which brings together geography, poetry, design, and visual art in a series of maps that evoke the poetic effects of one neighborhood. In his forward to Everything 
Sings, Ira Glass writes that Wood takes "a form that's not intended for feeling or mystery and make[s] it breathe with human life" (Glass, 2013: 11). Wood maps light and shade, smell and soundscape, holiday decorations, and the routes of rubbish collection and postal delivery as intimate choreographies between people and spaces. This approach to mapping "somehow makes our world seem fragile and very precious" (Glass, 2013: 11) and provides an instance of interdisciplinary thinking that could enable the "countercultural kind of perceiving" that philosopher Jane Bennett (2010: xiv) proposes humans need in order to recognize interconnectedness between not only living creatures but also with the objects which co-constitute the assemblages that are our selves.

\section{Mapping cultural intangibles}

The special issue theme of "Cultural Mapping: Making the Intangible Visible" is a key dimension of current research within cultural mapping. This area of research focuses on mapping the intangibilities of a place (e.g., stories, histories, etc.), those aspects that provide a "sense of place" and identity to specific locales, and the ways in which those meanings and values may be grounded in embodied experiences. It aims to capture those elements that are not easily counted or quantified, but are key to understanding a place and how it is meaningful to its residents and visitors. The topic has implications for artistic, architectural, and planning practices and agents.

The articles selected for this issue present diverse perspectives for mapping cultural intangibles, collectively addressing emerging issues through using cultural mapping methods as: a means for strengthening local communities; ways of fluidly shifting between local and global perspectives; modes for attending to place; and practices for understanding relationships between communities, spaces, times, and histories. In an age of instantaneous global communication and threats of homogenized cultural environments, concern for mapping intangible knowledges, spaces, cultures, and practices is growing internationally, with an eye not only to documenting and preserving this information but also to catalyzing and propelling place-embedded cultural traditions and knowledges into the future, constructing the scaffolding for pluralist cultural sustainability. At the same time, cultural mapping is also being used as a methodology for better understanding the contemporary urban environment - the senses of place, of flows and pace, and of changes.

These practices are framed by the multidisciplinary approaches of cultural mapping traditions (see Duxbury et al., 2015) and informed by insights gleaned from diverse fields that are also grappling with identifying, presenting, and mobilizing intangible dimensions and elements, such as intangible cultural heritage, creative research, and education. It is to these allied areas that we now briefly turn.

\section{Considering cultural intangibles: UNESCO legacies}

The most commonly referenced body of work on intangible dimensions of culture relates to UNESCO's work on intangible cultural heritage, which is rooted primarily in the 2003 Convention for the Safeguarding of Intangible Cultural Heritage (UNESCO, 2003a) and secondarily in the 2005 Convention on the Protection and Promotion of the Diversity of Cultural Expressions (UNESCO, 2005). UNESCO views intangible cultural heritage (including both inherited and contemporary practices) as actively rooted in communities and dependent on knowledgeable individuals passing on their knowledge of traditions, skills, and customs to others in the community, from generation to generation, or to other communities (UNESCO - Bangkok Office, 2015). The accent here is on "processes and the knowledge and skills required for the enactment, very often - literally - for the embodiment of intangible cultural heritage elements" (Smeets \& Yoshida, 2005: 4). Ensuring viability and transmission are thus the key foci, surrounded by a range of actions linked to "safeguarding": "identification, documentation, research, preservation, protection, promotion, enhancement, transmission, particularly through formal and informal education, as well as the revitalization of the various aspects of such heritage" (UNESCO, 2003a; Art. 2.3).

The identification and documentation aspects of this work are linked to the responsibility of signatory States to create a national inventory with the participation of communities, groups, and relevant NGOs. As Crawhill (2007) points out, this exercise "creates an opportunity: to negotiate not only greater recognition of oral cultures and intangible heritage, but also to explain the close relationship existing between different cultural heritages and the territory and natural resource contexts in which cultural heritages arise and survive" (pp. 7-8).

While a variety of approaches to creating inventories and registries exist, techniques of Participatory Geographic Systems (PGIS) used for community mapping have been considered promising (Crawhill, 2007; Smeets \& Yoshida, 2005). From the beginning, however, it has been realized that approaches to mapping intangible cultural heritage assets would have to differ from the standard methods concerning tangible cultural assets. Expanding from the initial focus on creating inventories, UNESCO's views on cultural mapping now incorporate individual and collective interpretations of culture and how these cultural dimensions influence people's perceptions of places. Cultural mapping, used in both a literal and metaphorical sense, is viewed as going "beyond strict cartography to include not only land, but also other cultural resources and information recorded by alternative techniques" (UNESCO - Bangkok Office, 2015: n.p.).

Within this stream of practice, UNESCO has expressed a particular interest in the carrying out of cultural mapping projects by indigenous communities to help revitalize and transmit cultural knowledge as well as to build community cohesion and enable better management of cultural resources (UNESCO, 2003b; Crawhill, 2007). These projects have critiqued mainstream approaches to cultural resource management and contributed to more nuanced understandings of culture as it is embodied in real places and among members of real communities. And, over time, some of the lessons learned and pathways forged in these projects have seeped into the interdisciplinary field of cultural mapping.

For example, the Cultural Resources Audit Management (CRAM) approach developed by the South African San Institute highlights that the knowledge base may be fragmented with unequal access to cultural resources; values a community's intellectual capacity and its self-defining of significant resources; and prioritizes the epistemology and cultural framework of non-dominant indigenous knowledge systems in identifying and locating "what is of value to the community's financial and spiritual well-being" (Crawhall, 2001: n.p.). Within this approach, intangible cultural heritage is defined as

that which exists intellectually in the culture. It is not a physical or tangible item. Intangible heritage includes songs, myths, beliefs, superstitions, oral poetry, as well as various forms of traditional knowledge such as ethnobotanical knowledge. For the southern Kalahari San, each tree and many other physical sites are part of their intangible heritage as their history is associated with these sites through stories, names and songs....

In turn, cultural resources are defined as that with a current application, which the community may draw upon: "Cultural 
resources include traditional indigenous knowledge systems, but also song, dance, knowledge of community history and experience, the ability to interpret events from a particular, culturally-informed position, etc." (Crawhall, 2001: n.p.). The process of auditing or inventorying intangible cultural resources serves, in the immediate time frame, to create "tangible materials that help represent, explain and manage what is otherwise invisible ... [in order] to help audit what is at risk and create media to help others learn and appreciate that which was previously invisible" (Crawhall, 2001: n.p.). It is in this spirit that we examine the mapping of cultural intangibles in this issue.

Leading approaches to cultural mapping today tend to acknowledge the shifting and fragmented nature of many communities and aim to reflect and privilege pluralistic local knowledges, perceptions of importance, and ways of understanding - important dimensions of the projects and analyses in the articles selected for this issue. Extending from this, they aim to draw connections and articulate relationships between people and place, culture and nature.

Moving beyond anthropocentric perspectives addresses a bias inherent in many UNESCO-informed or creative industry-focused approaches, that is, the focus on intangible cultural heritage and creation, which excludes many elements of intangibility from this scope. Echoing the inclusion of tangible natural features within the cultural intangible landscape, but aiming to extend beyond this, the special issue attends also to more-than-human understandings of intangibility, such as environmental, spatial, and ecological frames, which allow us to understand our living spaces and the relationships and intensities that occur between people and places. Although eco-cultural mapping approaches appear to be more commonly implemented within rural territories (see, e.g., Gaia Foundation, 2015), we argue that similar perspectives can be adapted for urban areas.

\section{Dissolving the theory-practice binary in creative research}

In the fields of art and educational research, methodologies are rapidly growing and shifting as practice-led and creative research methods become more accepted and commonplace. Haseman (2007) discusses the term practice-led research as a relatively recent methodological term that "asserts the primacy of practice and insists that because creative practice is both ongoing and persistent, practitioner researchers do not merely 'think' their way through or out of a problem, but rather they 'practice' to a resolution" (p. 147). The development of creative practices as forms of knowledge in themselves has led to a paradigm shift that has challenged logocentric assumptions of knowledge and created space for embodied, transitional, relational, and live research work. Performance researcher Carol Brown discusses this move as embracing the "messy materiality of bodies" and the complexity, ambiguity, and ephemerality of creative processes and their modes of articulation (Brown, 1997: 135).

As the paradigm of practice-led or artistic research has grown, so has the diverse range of forms for articulating practices, rehearsal processes and studio techniques, collaborative, interdisciplinary forms of decision-making and other kinds of knowledge particular to creative labor. Cultural mapping, as both methodology and form of research articulation, is becoming a valuable tool in artistic research through offering a way in which to create multimodal documents wherein examples of practice can interweave with critical and reflective writing. One of the issues facing artistic researchers in the academy is the tendency to create artificial barriers between practice and theory, wherein researchers' expected outputs will be separated, with an artistic or performative practical component accompanied by a theoretical exegesis. Yet practitioner- researchers consider artistic work as generating theory, just as writing is a form of creative practice. Cultural mapping offers possibilities for dissolving these binaries, allowing different modes of thinking and practice in a research project to sit alongside and inform each other through hybrid digital documents that interweave media and knowledges - sound files, moving and still images, modes of writing, and visual design (Duxbury \& Saper, 2015). Forms of digital mapping have the potential to allow the rich complexity, ambiguity, and ephemerality of creative processes to stay intact without being separated by splitting theoretical and practical thinking.

\section{Intangible vs. tangible learning outcomes}

Research into intangibilities is also a key area for innovative work in the field of education and there is a growing body of inquiry into "invisible learning outcomes." Disciplinary-specific forms of assessment tend to focus on the acquisition of measurable professional skills, and to leave out "softer," less tangible skills such as communication, self-efficacy, professional readiness, cultural sensitivity, empathy, curiosity, openness, risk-taking, or thinking from multiple points of view. These are, for the most part, invisible on academic transcripts - and to employers and students themselves. As Velasco (2012) states, we still "know little about the role of the educational institutions in the development of noncognitive skills" (p. 505). University assessment processes tend to enter measurable learning outcomes into quantifiable markers of success, while unmeasurable outcomes often go largely ignored. This is in spite of their vital importance in equipping students for the changing landscape of professional and personal life in the 21 st century with its undeniable, latent, and currently unimaginable environmental and social challenges.

Paterson and Barton (2013) consider the mantis shrimp as a metaphor for coming to appreciate intangibilities - the elements that are present in a setting but which generally go unnoticed:

The mantis shrimp is the world champion of color vision. It has such good eyes it can perceive both polarized light and multispectral images. If you combine the number of visual pigments with the other filters it has in its eye, it can distinguish sixteen different types of pigments. We only have three, leaving us wondering what the mantis shrimp perceives that we are prevented from seeing. (p. 1)

With insight into intangible aspects of knowledge, educational researchers and institutions gain a fuller picture of student capabilities and are more able to develop pedagogies for supporting students' diverse future careers. Paterson and Barton (2013) state that, "improving our ability to discern learning outcomes remains an urgent task" (p. 2). Their recent research project LUMOS aimed to identify those skills that might not show up on grade point averages but underpin many key professional abilities, such as the skills to collaborate, persevere, think in new directions, and act on instinct. They characterize their research practice, focused on appreciating diverse learning outcomes currently going "under-theradar" of tertiary education institutions, as aiming to open the spectrum of what it is possible for researchers to see. The LUMOS project has the potential to extend what educational practitioners are able to appreciate as knowledge in their learning spaces and thus to influence their awareness of the kinds of skills teachers can foster through specific teaching practices.

The articles in this special issue each bear similarities to the work of Paterson \& Barton in their intention to make visible an array of invisible or barely-visible qualities, practices, cultures, resources, and places. Each of the research projects discussed 
involves the development of cultural mapping instruments that allow an extension of vision through inquiry into how we can notice in innovative ways.

\section{The articles}

The opening article, "Cultural Mapping as a Development Tool" by Raquel Freitas, draws our attention to the objectives and strategic ambitions that underlie, inform, and structure cultural mapping projects. The focus of critical analysis is cultural mapping as a tool or instrument in the service of "development" contexts, considered here in regards to cultural policy research and community development. The article highlights distinctions between instrumental, utilitarian approaches in line with "cultural industry intelligence," and humanistic, integrated approaches in line with what has been developing as the conceptual and applied field of cultural mapping. By way of assessing and contrasting two "ideal type" cases in order to explore the challenges and potential of different approaches to cultural mapping, Freitas proposes a framework of analysis for assessing different types of cultural mapping cases.

As part of this analysis, Freitas explores how different approaches propose different means for reflecting on intangible aspects of culture and the challenges of incorporating these aspects into "the more tangible and utilitarian needs of public policy planning." This addresses an essential issue in the cultural mapping debate: how to turn intangible cultural practices into indicators, making them more "tangible and more standardizable elements" that can be used for mapping and planning purposes. Freitas points to the issue of ascribing value, or value creation, within a society as key to translating the intangible into tangible, asking: What type of value is cultural mapping creating? And what approaches are used to assess intangible cultural value? Responses to these questions are shaped by the development model driving the process, the level and directionality of analysis (i.e., top-down or bottom-up), and different views of culture.

"Less tangible" aspects of culture are generally aligned with "more intrinsic and essentialist" cultural mapping approaches that are amenable to qualitative perspectives, in contrast with "utilitarian and materialist" approaches that focus more on the tangible and quantifiable aspects of culture. In her analysis, Freitas reflects on complementarities between the approaches and their potential impacts. She concludes that an explicit recognition of the specificities of different cultural mapping approaches is essential so to enable a "more circumscribed and conscious orientation" of the methodologies used and their integration into common research objectives. This work requires that researchers consider, in particular, contrasts and complementarities in terms of quantitative/ qualitative, a focus on economic growth vs. human development, and tangible/intangible aspects.

Darko Radović's paper, "Measuring the Non-Measurable: on Mapping Subjectivities in Urban Research," discusses the Mn'M Project (Measuring the Non-Measureable), which brought together 10 research teams based in Tokyo, Hong Kong, Bangkok, and Singapore in dérive experiments exploring methods of mapping the affective, sensual, and ephemeral complexity of urban spaces, specifically focusing on those generally overlooked, intangible "subtleties that make some of the most fragile, most beautiful and most precious dimensions of the urban." The outcome of these research experiments was a series of maps, sketching possibilities for urban engagement through non-linear, multi-layered pieces of writing and image.

Like Freitas, this paper also explores issues of value - and specifically addresses embodied, ephemeral, transitory, tactile, and affective elements as generally going "beneath the radar" of urban planning. He addresses this specifically through the methodology of the derivé or "drift," which draws on Situationist artist/philosopher Guy Debord who writes, "it is no longer a matter of precisely delineating stable continents, but of changing architecture and urbanism" (Debord, 1958: n.p.).

Here, mapping takes the form of digital images in overlapping montage and poetic language - like the embodied experience of the city, meaning is not precise but felt, layered in the form of a provocation rather than a direct description, engaging poetic and abstract linguistic and graphic vocabularies in order to find space at the edge of communication for these generally under-valued registers of urban life. Drawing on Gilles Deleuze's discussions of intensity (Deleuze \& Guattari, 1987), Radović's maps focus on

bottom-up empowerment and the opening of our disciplinaryrestricted mapping practices to innovative, creative, radical and, of course, politically incorrect energies and voices of the urban. Such expansion challenges the entrenched practices of gatekeeping and seeks radical reinvention of the noteworthy, of what really matters in production of space. Even at the "sketchy" level, new practices open up new questions, and thinking about the answers starts to make the new paradigm look closer.

Different forms of making sense allow space for multiple forms of knowledge. The Mn'M project's aim to articulate the impossible allows a space for the creation of innovative methodologies, forms of analysis, and forms of dissemination. This will challenge many established definitions of what constitutes good research - issues of clarity, structure, style, and sense are raised in this piece. The article makes a dynamic argument for engaging with ambiguity, emergent design, sensuality, intensity, and subjectivity in urban research.

The "Measuring the Non-Measurable" project also highlights how, in the context of increasing numbers of urban renewal and revitalization projects, there is a real danger that the sense of an original historical and cultural identity of the area may disappear during the development process. In "Mapping the Pig Tale Journey: A Multidisciplinary Design Framework for Cultural Mapping in an Old Abattoir," Kirsi Eräranta, Tomi Leino, Tuuli Seppälä, Sandra Viña, and Eija Timonen directly address this challenge, developing a multidisciplinary design framework for mapping culture. Their project is focused on a group of "relic buildings" within a large urban renewal and redevelopment area and is interwoven with cultural planning and place design activities. Incorporating artistic and design methods, their approach aims to recover and reinterpret local cultural elements in sites undergoing transformation in order to foster a "constructive sense of place identity and identification," and to draw attention to ways in which intangible cultural resources of a place could be brought into interaction with its users, grounded in "affective and embodied experiences."

Drawing on cultural studies, screenwriting, scenography, and service design, Eräranta et al. base their work on the view that "the identity of a place is narratively constructed by the meanings that people give to it on the basis of the actual physical and social place and its history," a view shared by Cauchi-Santoro and Okano (in this issue). Through telling stories - creatively assembling, interpreting, and reinterpreting "various meanings, episodes, experiences, and understandings within narrative" - people actively and creatively engage in "processes of producing identities." These place identities, the authors contend, can be strengthened by design activities.

The incorporation of the audience/customer perspective within a cultural mapping methodology is particularly noteworthy, drawing attention to and aiming to improve audience reception and 
engagement with the results of cultural mapping activities. This aspect is commonly downplayed with attention more focused on the processes of creating the map than on the reception and use of the findings of cultural mapping projects.

In this case, the mapping process involved on-site observations, attending to researchers' perceptions and experiences, social interactions and everyday life occurring at the site, and evocative details of place such as the names used, architectural details, links to surrounding areas, and media content. Researchers collected visual materials through videotape, photography, and drawing, which was complemented by discussions with site users and semistructured thematic interviews with actors responsible for different premise operations, an activating user study for visitors to the site, and archival and historical research about the site. In this context, cultural intangibles include traditions, stories, values, and meanings, both relating to the past and to aspirations for the future of the site. The process of data collection and analysis followed the ideas of hermeneutics (Gadamer, 2004).

Mapping results were expressed in a narrative and site-specific form, incorporating affective, visual, and spatial elements. Outcomes from the analytical process included a "thematic customer journey map" consisting of a visually expressive geographic map and a site-specific intervention realized through a scenographic production in the form of a narrative walking tour. The article raises questions on how processes of cultural mapping might assist in catalyzing a sense of place through "affective and embodied experiences," leading us to reflect on the role of live activities and imaginative interpretations in distilling and articulating intangible values.

In "Story-telling about Place: Engaging Citizens in Cultural Mapping," M. Sharon Jeannotte investigates citizen-based community story-telling initiatives in Ontario, Canada, that aimed to uncover the intangible cultural dimensions of their communities. In the tradition of oral history over generations, these story-telling projects aimed to carry on this legacy, to preserve and share the local history, identity, ways of knowing, and knowledge for future generations. Jeannotte roots this activity in UNESCO intangible cultural heritage traditions, but also links it to contemporary research investigating the inclusion of cultural values within an "ecosystem services" framework, suggesting that "sustainable development" tends to be more closely tied to intangible cultural assets than tangible assets. She recommends that cultural mapping is understood as a "first step in a longer journey toward cultural sustainability."

The "stories of place" tend to focus on spiritual values, cultural identity, social cohesion, and heritage values, including stories about "early settlers, vanished industries, and cultural iconography." They intertwine culture, social, and environmental elements, tying intangible cultural narratives to particular places - locations of creative inspiration, aspects that make a place "special," and those that define unique characteristics of the locale. The projects use a narrative approach to collect, codify, and showcase local stories, tending to highlight positive aspects, and leaving the visitor to "read between the lines to understand or grasp the significance of less positive elements" - reflecting the messy and contested dynamics of the local cultural eco-system in which they are embedded. The main modes of presentation involve video that "allows the viewer to absorb the mood of the place, rather than its detailed stories"; photographs, paintings, and drawings; stories captured through audio; and written texts.

These intangible cultural asset-mapping initiatives are in an early stage of development, however, with evident challenges in maintaining community engagement in the long-term, as well as challenges to "codifying the un-codifiable." Jeannotte also recognizes operational challenges in taking up these articulations of "unique characteristics of place" into decision-making and planning realms, reflecting Freitas' concerns.

In "Mapping Community Identity: Safeguarding the Memories of a City's Historic Core," Roberta Cauchi-Santoro addresses issues that have become central to debates about cities and culture: heritage preservation and memory, citizen participation in local planning processes, and local identity in the face of tendencies toward global uniformity. The study on mapping intangible culture in the historic core built onto and extended a previous "tangible assets"focused cultural mapping project of the city of London, Ontario, Canada. The focus of Cauchi-Santoro's study is on showing how tangible and intangible assets go "hand in glove."

The project's ethnographic research approach (based on interviews) is informed by the works of Pierre Bourdieu (1993), who argues against various kinds of dualism in the study of culture, and by thinking about space as socially constructed and contested (e.g., Fraley, 2011) and language as the means through which a world arises (Heidegger, 2001). Cauchi-Santoro construes the historic district as "a collection of narratives anchored to places of collective significance" and, by extension, the community identity of the area. The study compiles narratives about buildings and about what happened in specific buildings to develop rich accounts of the "historical meanings" of these sites. The narratives are those active in living memory, i.e., living history, articulating the "older layers of lived experience" associated with thirty of the oldest heritage buildings in the downtown district. The goal of the research is to provide these historical meanings associated with place while also contributing to the civic pride and sense of identity of local citizens, potentially drawing them into and influencing planning processes concerning heritage preservation.

Cultural mapping becomes a means for "making intangible heritage more visible and understandable, including information excluded by mainstream documents or unrecognized in official power structures" (Cauchi-Santoro). In this context, the project of mapping "ancestral cultural heritage" becomes one akin to counter-mapping, aiming to discover "forgotten knowledge," capturing the subjective perceptions, ephemeral phenomena, and ineffable significance of local memories and, through this, highlighting alternative meanings of space and place. The narratives are heavily dependent on individuals' interactions in their community and the trustworthiness of personal and collective memory. The collection of first-hand observations and stories, perceptions of past city planning decisions, and the history of social and cultural issues linked to specific buildings enables a community-driven picture of value and place-based meanings to emerge - one that is clearly distinct from the municipality's point of view.

One issue that the project faced was the danger that the process of "capturing" the stories might "fossilize" the shared knowledge and experience, and in the process trivialize this living culture. To address this, the project strives to link the research findings to multiple strategies and plans, with notable interest from municipal planners. However, at the moment many of these linkages appear to be informal, potential uses rather than being built into the original design of the project, requiring the promotion of continued, active engagement with the findings. As well, the project uses an "open" platform, encouraging additional contributions from the community to diversify and "thicken" the map - as Jeannotte points out (in this issue), however, maintaining an active site over time is a significant challenge.

A related issue is the relevance of such work to newcomers to the city, and Cauchi-Santoro highlights two perspectives that emerged. On one hand, the "discovered value" of historic homes and buildings and the "de-familiarized" perspectives of 
international students resident in the city engendered renewed interest, also resulting in rediscovered pride by old-time inhabitants. On the other hand, some immigrant residents do not identify with the community's history, and this highlights the need for concerted, ongoing efforts not only to recuperate long-ignored cultural capital in the community but also to "regenerate" the community and to recognize this "new" heritage, continuing to build new layers of lived experience without erasing those that preceded.

Concluding the issue is Hiroshi Okano's "Cultural Editing for Creativity: A Framework to Associate Person/thing, Event, Road and Memories," which highlights how new ideas add to rather than replace the old in a process of infinite continuity. His article attends to the relationships between people, objects, and places through the specific lens of Japanese concepts such as the principle of "binary oneness rather than binary opposition," awase (to coexist), kasane (to overlap), kisoi (to compete), soroe (to integrate), and zurashi (displacement). Both Okano and Radović attend to the possibility for new thinking activated in processes of translation between languages, cultures, and moments through the mapping process. They highlight that this involves displacement and fracture as well as connectedness and understanding, and that both kinds of action can be generative of insight into culture and place.

Okano employs a methodology of "cultural editing" akin to Foucault's concept of archeology, which he defines as "a method for separating faults in discursive practice and formularizing laws that generate and transform that practice so as to 'unearth' discontinuous surfaces among various intellectual systems and convert what was previously invisible into what is visible." Rather than describe a specific mapping outcome, Okano's article provides a framework for attending to relationships between people, places, and things that has relevance to the field of cultural mapping, particularly in bridging spaces between eastern and western ontologies.

\section{Contributions and next steps in an interdisciplinary field}

Each of the articles in this special issue presents a research practice that has potential to widen the spectrum of what it is possible for researchers (and others) to see, some through specific applied projects that present examples of how cultural mapping theory can be translated into practice, and some through theoretical discussion ruminating on ways in which language and space can interplay, allowing generally overlooked aspects of the urban to be moved to the center. Taken together, these articles present a series of methods for noticing in innovative ways and facilitating fluid maps that function to create relationships for navigating between living creatures, spaces, and cultures. The maps emerging from these works do not propose to make physical spaces static, to connote ownership, or to articulate territory. Instead, they aim, in various ways, to highlight the dynamic lives of places in their complexity, diversity, and richness.

The desire to "make visible" the intangible dimensions of culture that are entangled with place-based meaningfulness without "fossilizing" them presents a significant challenge to frameworks of traditional cartographic practices. The conceptual and methodological directions presented in this issue provide some avenues through which these challenges are being taken up within the interdisciplinary field of cultural mapping. A key dimension that emerges is the necessity to closely attend to the dynamics that are revealed, forces that may transform this knowledge in processes of reinterpretation, translation, and reuse - propelled into the future as well as utilized in the current day to better understand and narrate the world around us. As a bridging methodology, cultural mapping holds great potential as a powerful agent to both share and catalyze place-specific knowledges into new trajectories and actions. The methods that are created to address such complex roles and situations may challenge norms of research, structure, and presentation while innovating new "mash-ups" of approaches to research, analysis, documentation, interpretation, and communication to multiple publics. In these processes of exploration and advancement, critical and imaginative attention to the contributions, biases, and complementarities of different approaches will become increasingly important.

As the field of cultural mapping continues to grow, allowing new kinds of collaborations across research disciplines, we look forward to encountering further examples of specific instances of practice on the ground. As these emerge we consider it important to have robust discussion of issues, tensions, and potentials opened up in transdisciplinary practices of cultural mapping, for example, in merging geography, artistic, and qualitative/quantitative methods. When paradigms and ontologies are merged, this usually involves dislocation as well as melding - making the processes as well as outcomes of research visible. All of the complexity and challenges that transdisciplinary methodologies provoke will do much to strengthen this field and contribute to its generative potential.

\section{References}

Bennett, J. (2010). Vibrant matter: A political ecology of things. Durham, NC: Duke University Press.

Bourdieu, P. (1993). The field of cultural production: Essays on art and literature. In R. Johnson (Ed.). New York: Columbia University Press.

Brown, C. (1997). Dancing between hemispheres: negotiating routes for the danceracademic. In L. Stanley (Ed.), Knowing feminisms. London: Sage.

Carter, P. (2009). Dark writing: Geography, performance, design. Honolulu: University of Hawai'i Press.

Crawhall, N. T. (2001). Written in the sand: auditing and managing cultural resources with displaced indigenous people. Cape Town: South African San Institute (SASI) http://www.san.org.za; http://www.sanculture.org.za/body.htm Accessed 09.2015 .

Crawhill, N. (2007). The role of participatory cultural mapping in promoting intercultural dialogue - 'We are not hyenas'. Paris: UNESCO. http://portal.unesco.org/ culture/en/files/37746/12197593145The_role_of_participatory_cultural mapping_in_promoting_intercultural_dialogue.pdf/The\%2Brole\%2Bof\% 2Bparticipatory\%2Bcultural\%2Bmapping\%2Bin\%2Bpromoting\%2Bintercultural\% 2Bdialogue.pdf Accessed 07.2015.

Debord, G. (1958). Theory of the dérive. Internationale Situationniste, 2.

Deleuze, J., \& Guattari, F. (1987). A thousand plateaus: Capitalism and schizophrenia. Minneapolis: University of Minnesota Press.

Duxbury, N., Garrett-Petts, W. F., \& MacLennan, D. (2015). Cultural mapping as cultural inquiry: Introduction to an emerging field of practice. In N. Duxbury W. F. Garrett-Petts, \& D. MacLennan (Eds.), Cultural mapping as cultural inquiry. New York: Routledge.

Duxbury, N., \& Jeannotte, M. S. (Eds.). (2015). Special issue: Cultural mapping in planning and development contexts, Culture and Local Governance, 5 pp. 1-2).

Duxbury, N., \& Saper, C. (2015). Introduction: mapping culture multimodally. Hyperrhiz, 12. http://hyperrhiz.io/hyperrhiz12/introduction/introduction.html Accessed 09.2015.

Fraley, J. M. (2011). Images of force: the power of maps in community development Community Development Journal, 46(4), 421-435.

Gadamer, H. G. (2004). Truth and method ( $2^{\text {nd }}$ ed.). London: Sheed and Ward Stagbooks.

Gaia Foundation. (2015). Eco-cultural maps and calendars. http://www. gaiafoundation.org/eco-cultural-maps-and-calendars Accessed 09.2015.

Glass, I. (October 7, 2013). Denis Wood: emotional cartographer. Huffington Post. http://www.huffingtonpost.com/ira-glass/denis-wood-emotionalcartographer_b_3570084.html Accessed 12.2015.

Haseman, B. (2007). Identifying the performative research paradigm. In E. Barrett, \& B. Bolt (Eds.), Practice as research: Approaches to creative arts enquiry. London: Tauris.

Heidegger, M. (2001). Poetry, language, thought. New York: Harper Perennial.

Paterson, J., \& Barton, B. (November 24-29, 2013). Undergraduate mathematics outcomes: The mantis shrimp spectrum. Paper presented at Lighthouse Delta 2013: The $9^{\text {th }}$ Delta Conference on teaching and learning of undergraduate mathematics and statistics. Kiama, Australia. http://www.deltaconference.org/ documents/program/4A-2-Paterson2013.pdf Accessed 09.2015.

Smeets, R., \& Yoshida, R. (2005). Cultural mapping and the safeguarding of the intangible cultural heritage. Paris: UNESCO.

Stewart, S. (2007). Cultural mapping toolkit. Vancouver: Creative City Network of Canada and 2010 Legacies Now. http://www.creativecity.ca/database/files/ 
library/cultural_mapping_toolkit.pdf Accessed 09.2015.

UNESCO. (2003a). Convention for the safeguarding of the intangible cultural heritage. Paris: UNESCO. http://portal.unesco.org/en/ev.php-URL_ID=17716\&URL DO=DO_TOPIC\&URL_SECTION=201.html Accessed 09.2015.

UNESCO. (2003b). Mapping of indigenous cultural resources. Paris: UNESCO. http:// www.unesco.org/new/en/culture/themes/culture-and-development/unescoand-indigenous-peoples-partnership-for-cultural-diversity/cultural-mapping/ Accessed 09.2015.

UNESCO. (2005). Convention on the protection and promotion of the diversity of cultural expressions. Paris: UNESCO.

UNESCO - Bangkok Office. (2015). Tools for safeguarding culture: Cultural mapping. Bangkok: UNESCO. http://www.unescobkk.org/culture/tools-and-resources tools-for-safeguarding-culture/culturalmapping/ Accessed 09.2015.

Velasco, M. S. (2012). More than just good grades: candidates' perceptions about the skills and attributes employers seek in new graduates. Journal of Business Economics and Management, 13(3), 499-517. http://dx.doi.org/10.3846/ 16111699.2011.620150.

Wood, D. (2010). Everything sings: Maps for a narrative atlas. Los Angeles: Siglio.
Alys Longley ${ }^{\mathrm{a}}$, Nancy Duxbury ${ }^{\mathrm{b}, *}$ a Senior Lecturer, Dance Studies, University of Auckland, Private Bag, Auckland, New Zealand

b Senior Researcher, Cities, Cultures and Architecture Research Group, Centre for Social Studies, University of Coimbra, Colegio S. Jeronimo, Ap. 3087, Coimbra, 3000-995, Portugal

* Corresponding author. E-mail addresses: a.longley@auckland.ac.nz (A. Longley), duxbury@ces.uc.pt, duxbury@sfu.ca (N. Duxbury).

16 December 2015 Available online 13 January 2016 